\title{
A spectroscopic study of laser-induced tin-lead plasma: Transition probabilities for spectral lines of Sn I
}

\author{
A. Alonso-Medina \\ Departanento de Fisica Aplicada, EUT industrial, Universidad Politécnica de Madrid, Ronda de Valencia 3, 28012 Madrid, Spain
}

A R T ICLE I N F O

Keywords:

Lasel-induced plasma spectroscopy

Plasma diagnostic

Transition probabilities

Tin

\begin{abstract}
A B S T R A C T
In this paper, we present transition probabilities for 97 spectral lines of $S n$ l, comesponding to transitions $n$ $(n=6,7,8) s \rightarrow 5 p^{2}, n(n=5,6,7) \mathrm{d} \rightarrow 5 \mathrm{p}^{2}, 5 \mathrm{p}^{3} \rightarrow 5 \mathrm{p}^{2}, n(n=7) \mathrm{p} \rightarrow 6 \mathrm{~s}$, detemined by measuring the intensities of the emission lines of a Laser-induced breakdown (emission) spectrometry (LIBS). The optical emission spectroscopy from a laser-induced plasma generated by a $10640 \mathrm{~A}$ radiation, with an irradiance of $1.4 \times 10^{10} \mathrm{Wcm}^{-2}$ on an $\mathrm{Sn}-\mathrm{Pb}$ alloy (an $\mathrm{Sn}$ content of approximately $20 \%$ ), in vacuum, was recorded at $0.8 \mu \mathrm{s}$, and analysed between 1900 and $7000 \mathrm{~A}$. The population-level distribution and corresponding temperature were obtained using Boltzmann plots. The electron density of the plasma was determined using well-known Stark broadening parameters of spectral lines. The plasma under study had an electron temperature of $13,200 \mathrm{~K}$ and an electron number density of $2 \times 10^{16} \mathrm{~cm}^{-3}$. The experimental relative transition probabilities were put on an absolute scale using the branching ratio method to calculate $\mathrm{Sn}$ l multiplet transition probabilities from available radiative lifetime data of their upper states and plotting the Sn I emission spectrum lines on a Boltzmann plot assuming local thermodynamic equilibrium (LTE) to be valid and following Boltzmann's law. The LTE conditions and plasma homogeneity have been checked. Special attention was paid to the possible self-absorption of the different transitions. The experimental results obtained have been compared with the experimental values given by other authors.
\end{abstract}

(c) 2010 Elsevier B.V. All rights reserved.

\section{Introduction}

The determination of the transition probabilities for spectral lines is a vast field of research on account of its considerable interest in atomic structure research, laser physics, plasma physics, thermonuclear fusion research and applications to astrophysics. A detailed investigation of high-resolution astrophysical spectra requires a large number of accurate atomic data. Tin is an important element in laboratory diagnostics, e.g. recently in semiconductor lithography tools $[1,2]$ and in cosmic plasmas [3].

Tin neutral atom energy levels have been the subject of a few experimental and theoretical studies. Oscillator strengths of $\mathrm{Sn} I$ have been published previously by Corliss and Bozman [4], Penkin and Slavenas [5] (using the hook method) in 1962, have measured the absolute $f$-values of 29 Sn I lines in the spectral range of $2200-3200 \AA$. with an error of about $9 \%$, except for resonance lines, with an estimated measurement error of $14 \%$. In 1965 Lawrence et al. [6] used the atomicbeen-technique to measure the absolute f-values of six lines for multiplet $5 \mathrm{p}^{2}{ }^{3} \mathrm{P}-6 \mathrm{~s}{ }^{3} \mathrm{P}$ in the spectrum Sn I. In 1967 Ovechkin et al. [7] determined transition probabilities for 11 spectral lines of $\mathbf{S n}$ l. DeZafra and Marshall [8] have obtained experimental absolute oscillator strengths for 4 spectral lines of neutral tin. Lotrian et al. [9] (in arc

E-mail address: aureliaalonso甲upm.es. discharge) have obtained transition probabilities in the spectral range of $2400-4000 \AA$ for 17 spectral lines of Sn I. Wujec and Musielok [10] have measured absolute transition probabilities for 39 lines of Sn I for 26 lines, error $20-25 \%$, and for the remaining lines $50 \%$, using emission spectroscopy, in ultra-violet and visual spectra region. Wujec and Weniger, in 1977, [11] determined absolute transition probabilities from the emission spectra produced in a wall-stabilized arc for fifteen lines of $S n I$ in the spectral range od $5300-6850 \AA$, with estimated errors of about $40 \%$. Miller et al. [12] have determined transition probabilities from 9 spectral lines in the range of 3100-6000 $\AA$ (errors, $35-50 \%$ ). Muradov [13], in 1979, determined relative oscillator strengths of $\mathrm{Sn}$ I. A relativistic calculation of transition probabilities of the $n p(n+1)$ s and $n p^{2}$ configurations for $S n I$ was performed by Holmgren and Garpman [14] in 1974. Migdalek [15], in 1979, calculated the relativistic oscillator strengths for the $n p^{2} \rightarrow n p(n+1)$ $s$ transition array as well in Sn [ spectra in jj and intermediate coupling. Optical oscillator strengths for transitions $5 p^{2}-n s, 5 p^{2}-n d$ of $S n$ I have been calculated by Ganas [16] and for 14 lines of the $5 p^{2}-6$ s transition for Gruzdev [17]. Bieron et al. [18] in 1991, have calculated, using the relativistic configuration interaction $(\mathrm{Cl})$ approach, the oscillator strengths and excitation energies for the $n p^{2} \rightarrow n p(n+1)$ s transitions in $\mathrm{Sn}$ I. Energy levels and radiative transition probabilities for states within the $5 \mathrm{p}^{k}(k=1-5)$ configurations of atoms and ions in tin have been calculated by Biémont et al. [19]. In 1998 [20] and 2001 [21], Curtis estimated the branching fractions for the $n s^{2} n p^{2}-n s^{2} p(n+1) s$ 
transitions in Sn I, using intermediate coupling. Recently Yu et al. [22] have calculated oscillator strengths of neutral tin and Oliver and Hibbert [23] have calculated oscillator strengths using the atomic structure code CIV3 (Breit-Pauli configuration interaction) of transition in Sn L. Nadeen et al. [24-26] used two-step spectroscopy to investigate the even parity Rydberg levels of neutral tin.

Laser-induced breakdown spectrometry (LIBS) is a modern analytical technique based on emission spectroscopy that employs powerful laser pulses, focused on a sample, to attain representative vaporization and excitation, it has a fast response, as described recently in [27]. The analytical performance of the UBS technique depends heavily on the choice of the experimental conditions. Laser ablation for analysis of solid sample is one of the most important applications of Laser-induced plasma spectroscopy (LIPs) in science and technology by Radziemski and Cremers $[28,29]$. LIBS use a lowenergy pulsed laser ( $\mathrm{a}$ few hundred $\mathrm{m}$ ) to generate the plasma which vaporizes a small amount of sample. The interaction of a high-power laser beam with solid samples generates plasmas on the target surfaces with high temperatures and electron densities [30-32]. The emission spectrum of the plasma plume reveals important information regarding identification and quantification of the emitting species present in the ablated material. Plasma characteristics depend on laser intensity, wavelength and pulse duration, as well as on the physical and chemical characteristics of target material, and the surrounding atmosphere $[33,34]$. From the experimental point of view, LP has proved to be a valuable and versatile source of spectroscopic data on neutral and ionized species as has been shown, specifically, in tin [35-41].

In this paper, different plasmas (tin, lead and tin-lead alloy) are fully characterized, in terms of their appearance, emission spectra, electron temperature $\left(T_{e}\right)$ and electron number density $\left(N_{e}\right)$, in vacuum. This paper aims to provide new experimental values of transition probabilities for spectral lines of Sn I and provide experimental values from spectral lines in the range of 5000 to $7000 \AA$, with few estimated errors, while the values given in literature include uncertainties of up to $40 \%$. To obtain transition probabilities of Sn I, the experiment was carried out by emission of a plasma generated by focusing a laser beam on a solid sample of $\mathrm{Pb}-\mathrm{Sn}$ (with $80 \%$ lead purity and $20 \%$ tin purity), in vacuum, recorded with a $0.8 \mu \mathrm{s}$ delay time and at a fixed gate time of $0.1 \mu \mathrm{s}$, and analysed between 1900 and $7000 \AA$.

In this paper, we present transition probabilities for 97 spectral lines involving the levels of $S n I$ corresponding to transitions $n(n=6$, $7,8) s \rightarrow 5 p^{2}, n(n=5,6,7) d \rightarrow 5 p^{2}, 5 p^{3} \rightarrow 5 p^{2}, n(n=7) p \rightarrow 6 s$. Intensity relative values have been obtained from measurements of all emission line; we have used two different methods in order to place the data on an absolute scale. First, using experimental values, measured in literature, of the radiative lifetimes of the corresponding states (Branching ratios method). As far as we know, in the literature, radiative lifetime of only nine low-lying odd-parity levels in 5p6s and $5 p 5 d$ have been measured using different technique (phase-shift, Hanle effect, the zero-field level-crossing technique, beam-foil, electron-excitation DCM) [8,42-46], and lifetimes for nine levels of the $5 p 7 p$ configuration of neutral tin have been measured by the time-resolved fluorescence method for Zhang et al. [41] in 2008. Secondly, with the local thermodynamic equilibrium (LTE) assumption, several transition probabilities were placed on an absolute scale from the Boltzmann plot of $\mathbf{S n} I$ line intensities. The values obtained are compared with existing experimental and theoretical values. Also, the state of local thermodynamic equilibrium (LTE) is evaluated and plasma homogeneity has been checked.

This paper is organized as follows. Section 2 describes the experimental system used for LIBS, the procedure for obtaining the plasma and the study of the emission spectrum. The results obtained regarding the electron density and temperature of plasma, the LTE conditions, homogeneity of plasma in study, as well as transition probabilities of the $\mathrm{Sn}$ I spectra lines and analysis of the possible selfabsorption of the different transitions, are given in Section 3, and conclusions in Section 4.

\section{Experimental setup and procedure}

The experimental setup, has already been described in previous papers in detail [ $36,37,40,47-52]$, so only a brief description is given here. A schematic of our experimental setup is shown in reference [52]. The laser used in our experiment was a Q-switched laser Nd:YAG (Quantel YG585) of $7 \mathrm{~ns}$ pulse duration of $275 \mathrm{~mJ}$ at $10640 \mathrm{~A}$ with a frequency of $20 \mathrm{~Hz}$. The laser energy was monitored using a calibrated power-meter.

The laser beam is deflected by total reflection in a prism and is focused, with a quartz lens of focal distance of $12 \mathrm{~cm}$, the surface of the target placed horizontally, with a power density on the surface of $1.4 \times 10^{10} \mathrm{Wcm}^{-2}$, producing craters with standard diameters of $0.5 \mathrm{~mm}$.

A chamber was prepared to generate the plasma with the target in vacuum $\left(\sim 10^{-5}\right.$ Torr $)$. The chamber has a system for changing the target position, maintaining the vacuum, so the plasma is formed in each measurement on the smooth surface of the target and not on the crater formed in the previous measurement. It also features a quartz window through which the light is sent to the spectrometer entrance slit, located $8 \mathrm{~cm}$ from the plasma. The spectrometer used in the $1900-7000 \mathrm{~A}$ range was a Czerny-Turner, with a $1 \mathrm{~m}$ focal length and a, 2400 grooves/mm holographic grating; the fist-order resolution, for a slit of $50 \mu \mathrm{m}$, is $0.3 \AA$ which corresponds to 3 channels, a resolution that is hard to achieve and equipped with a gated optical multichannel analyser (OMA III EG\&G) system, which can be used to record sections of the spectrum with a delay with respect to the laser pulse and for a selected interval of time. The minimum duration of the time window is $200 \mathrm{~ns}$, and the spectral band detected by the device is about $100 \AA$.

The measurements were repeated at several delay times of $0.15-$ $9 \mu \mathrm{s}$ and at a fixed gate time of $0.1 \mu \mathrm{s}$, and consisted in the accumulation of 20 laser pulses at a delay time. To obtain the best signalto-noise ratio the measurements were made with a delay of $0.8 \mu \mathrm{s}$ and a recording interval of $0.1 \mu \mathrm{ss}$. The detection was performed in synchronized manner with the electronic device that regulates the laser Q-switch. The measurements were obtained, after ablative cleaning the target for 2 laser pulses, in order to remove impurities. In each data acquisition period a correction was made with regard to the dark signal in the absence of the laser plasma. The instrumental profile needed for the numerical analysis of each spectrum was determined from the observation of several narrow spectral lines from hollowcathode lamps, with a precision of $97 \%$. The distance for which two lines can be distinguished is $0.36 \AA$ in first order.

The lines studied ranged from 1900 to $7000 \AA$. The system has been calibrated in wavelength by recording the well-known lines of $\mathrm{Ar}$. Ne and $\mathrm{Hg}$ covering the wavelength range of $1900-7000 \AA$, the uncertainties in the measurement are $\approx 0.001 \AA$. To calibrate the spectral response of the system (efficiency) was obtained in the 1900 to $7000 \AA$ wavelength range by means of previously calibrated lamps. A deuterium lamp was used for the $1900-4000 \AA$ range, and a tungsten lamp for the $3500-7000 \AA$ range.

Also, light from the plasma is collected through a quartz lens in an optical fiber (UV fused silica, $1 \mathrm{~mm}$ diameter) which transmits it to the entrance slit of the spectrometer, see schematic in Fig. 1. The lens and optical fiber connector have been mounted on a telescopic spring that lets you vary their relative distance to coincide with the focus distance of the image of the plasma, keeping aligned plasma-lensoptical fiber. The support is mounted on an optical bench, allowing controlled horizontal and vertical movements, thereby varying the area of plasma whose image is detected in the optical fiber. The focal length of the lens and its distance from the plasma was chosen to produce an enlarged image $(f=5 \mathrm{~cm}$, located $s=17 \mathrm{~cm}$ from the plasma and $s^{t}=5.5 \mathrm{~cm}$ from the entrance of the fiber). The fiber 


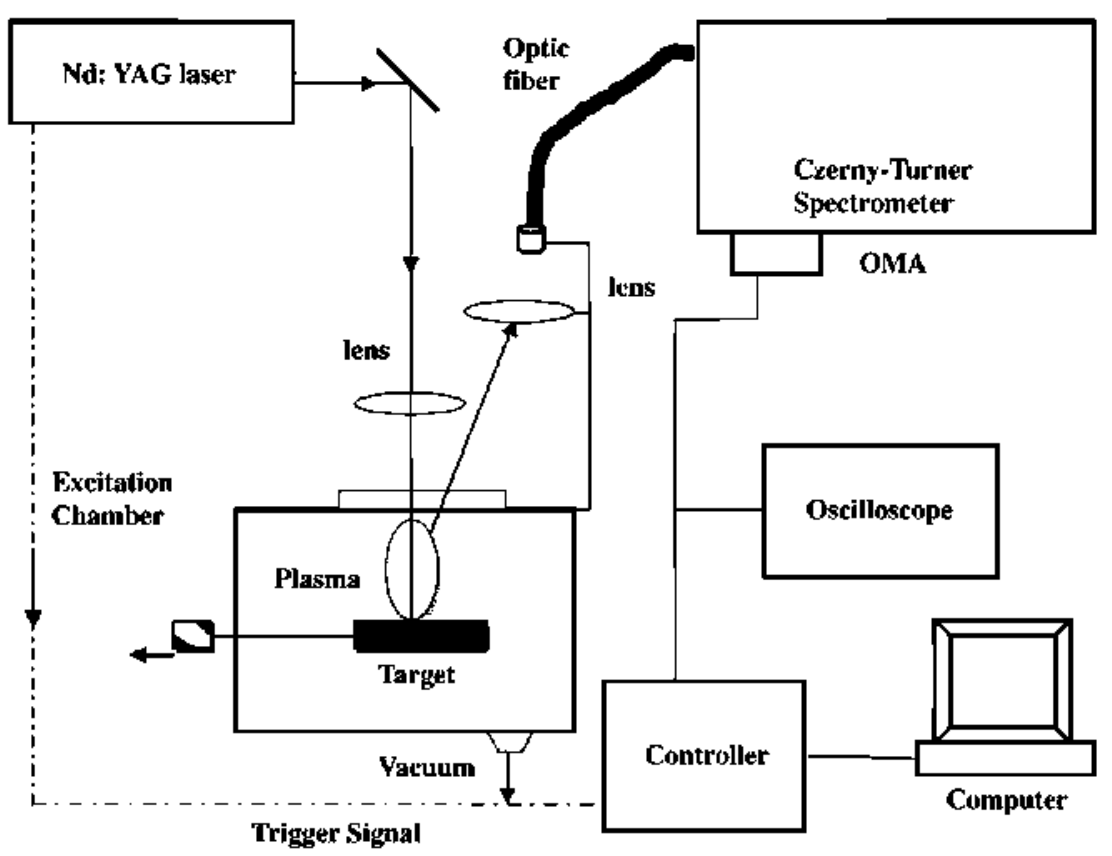

Fig. 1. Experimental setup for recording the LIBS spectra and study spatial resolution of plasma emission.

aperture receives the radiation spatially integrated throughout the emitting plasma volume. With this experiment, we have only obtained values for lines in the $3000-7000 \AA$ range, because as is well known, the refraction index of the optical materials depends on the wavelength producing changes in the lens focal length, which are important in the UV region. The fitting of the observed profiles provide the total intensity very accurately, as well as the broadening of the spectral lines. The values of transition probabilities for these lines, in the range 3000 to $7000 \AA$, were similar to those obtained with the previous experimental setup.

The two experimental setups have allowed light to be collected from different areas of the plasma. After several tests it was concluded that obtaining information about the transition probabilities in this study involved fist choosing the plasma area where the line intensity is greatest. The spectra were stored in a computer for further analysis. The spectra line analysis was performed by fitting the observed line shapes to numerically generated voigt profiles, with consists in the deconvolution obtained with the Lorentzian and Gauss profiles. For the plasma diagnostic, the area under each line profile from the aforementioned fitting represents the relative intensity.

The same experimental system was used to study the homogeneity of the plasma but, in order to obtain spatial resolution, as described above; the light was focused by means of a lens on a $1 \mathrm{~mm}$ light guide. facilitating selection of the point of the plasma from which the light emission was observed. The measurements were taken by scanning the plasma emission in two perpendicular directions, to determine where the different atomic species are located in the plasma and to determine the real plasma parameter values. Local profiles were obtained after Abel inversion of the integrated intensity [53].

The use of spectral lines in a wider spectral range requires the measurement of various spectral regions, leading to problems in assuring reproducibility between these measurements. In this paper, every intensity result has been measured five times. The reason for not measuring more times is that the variation in the intensity values remained almost constant so statistical uncertainty, ranging around 3\% depending on each line, was obtained.

In this paper, several types of experiments have been performed in order to obtain appropriate measurement conditions. In the first set of experiments, the time-resolved diagnostic technique has been used to study the emission spectrum of different plasmas (lead, tin, and lead- tin alloy) and check the evolution of different species. The LIP emission spectrum was recorded in vacuum for different delay times. In Fig. 2( $a$ and b), time-resolved emission spectra from laser-induced lead plasma, in vacuum, are presented. The spectra were recorded at 0.15-4.5 $\mu$ s after each laser light pulse, and analysed in the range of $3700-3790 \AA$ wavelength. In Fig. 2(b) is scaled from 0.7 to $4.5 \mu \mathrm{s}$.

At the initial state of the plasma, the spectrum lines appear widened, and it is hard to distinguish them from the intense bremsstrahlung continuum emission for times of approximately $0.1 \mu \mathrm{s}$. As seen, at short times the spectral emission lines of $\mathrm{Pb}$ I, $\mathrm{Pb}$ II and $\mathrm{Pb}$ III have appeared. Emission lines are broad mainly due the stark effect caused by the high density of free electrons. After a few hundreds of nanoseconds, characteristic atomic lines can be very clearly distinguished as the free electrons start to be captured by ions and neutral atoms and the highly excited species decay to lower energy levels. At the same time, line narrowing is observed as the major effects causing line broadening (collision and stark) become weaker. As the plasma expands and cools the relative intensities of the emission lines can change due to energy distribution among the plasma species [27]. For a time of approximately $0.2-0.4 \mu$ s after the laser pulse, the species observed are the ionized atoms $\mathrm{Pb}$ II and $\mathrm{Pb}$ III with high line intensities and widths and the most intense lines of $\mathrm{Pb} \mathrm{L}$. But the $\mathrm{Pb}$ III emission lines appearing at very early, times when the temperature of the plasma is higher, disappearing at $0.8 \mu \mathrm{s}$, the $\mathrm{Pb}$ II emission lines appear at very early times and disappearing in $1.5 \mu$ s and the $\mathrm{Pb}$ I emission lines appear also at very early times and disappearing in 5-6 $\mu$ s after the laser pulse. At $6 \mu$ is there is almost no presence of lead lines. It also shows that the plasma evolves faster in vacuum conditions than in another atmosphere. To conclude, the longer after the laser pulse, the more the widths and intensities of the neutral and single ionized species decrease, reaching maximum intensity to $0.8 \mu \mathrm{s}$.

In the second set of experiments, involving the study of pure tin and tin-lead samples, the process is similar. After a while, the emission signal is only representative of the most persistent lines of the elements present in higher concentrations in the sample. Fig. 3(a, b and c) presents a section typical spectra for the $2140-2240 \AA$ range, in vacuum, time-resolved emission spectra at $0.8-2.5 \mu \mathrm{s}$ from laserinduced lead-tin (concentration (a) 25\% Sn, (b) $95 \% \mathrm{Sn}$ and (c) $98 \% \mathrm{Sn}$ ) plasmas, and $\mathrm{Sn} \mathrm{I,} \mathrm{Sn} \mathrm{II,} \mathrm{Pb} \mathrm{I} \mathrm{and} \mathrm{Pb} \mathrm{II} \mathrm{emission} \mathrm{lines} \mathrm{may} \mathrm{be} \mathrm{observed.}$ Spectral lines of Sn I under study showed the maximum intensity is 

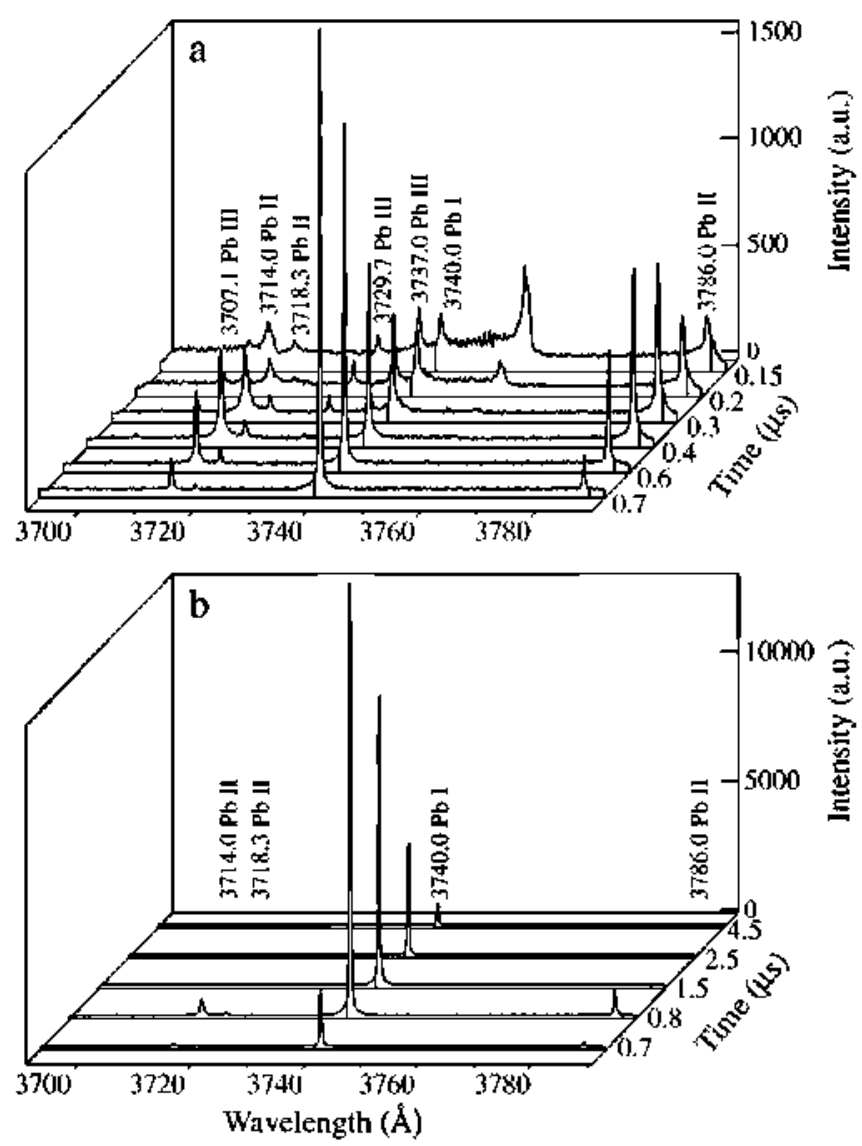

Fig. 2. (a and b). Time-resolved emission spectra section from laser-induced lead plasma, in vacuum and in the range (3700-3790) A wavelength. (b) is scaled from 0.7 to $4.5 \mu \mathrm{s}$.

reached at $0.8 \mu$ s delay time. In $4.5 \mu$ s, after the laser pulse, the tin practically disappears.

A major problem is self-absorption, which led to a reduction in the line intensities and greatly influences the transition probability values. The optical depth of spectral lines emitted by a LIP may be modified by changing the concentration of the emitting element in the sample. To prevent self-absorption effects, several alloys of tin and lead were used instead of pure tin for LIP generation and measurement of Sn I branching ratios: one of tin ( $99.9999 \%$ purity), another of lead ( $99.999 \%$ purity) and others obtained from several lead-tin alloy in different concentrations (with a tin content of $80-1 \%$ purity). Fig. 4 presents a section of typical spectra for the $2380-2460 \AA$ range, in vacuum, for different tin concentrations at $0.8 \mu$ s delay time.

To verify this requirement for the $\mathrm{Sn} I$ lines used in this paper, we have investigated the self-absorption effect in the plasma by measuring the line intensities for Pb-Sn samples with increasing Sn concentration $[30,54]$. Two typical intensity versus Sn concentration experimental curves for the $2421.7 \AA$ line, corresponding to the transition $5 p^{2}{ }^{1} D_{2}-5 d^{1} F_{3}$, and $2863.3 \AA$ resonance line corresponding to the transition $5 p^{2}{ }^{3} P_{0}-6 s{ }^{3} P_{1}$ of $S n I$, at 0.8 is delay time from laser pulse, are shown in Fig. 5(a and b), respectively. In Fig. 5a the high correlation of the lineal fitting $\left(R^{2}=0.99998\right)$ cam be appreciated and Fig. 5b displays the correlated of lineal fitting $\left(R^{2}=0.99982\right)$ corresponding to the solid line and the correlated of lineal fitting $\left(R^{2}=1\right)$ corresponds to the dotted line for intensity versus $S n$ concentration (1-20\%). The self-absorption effect from $25 \%$ Sn of concentration in the curve for this $2863.3 \AA$ resonance line. We can conclude that for tin contents lower than $25 \%$ a dependence of the measured branching ratios on concentration was not observed, so the measurements were made in optically thin conditions with an alloy of
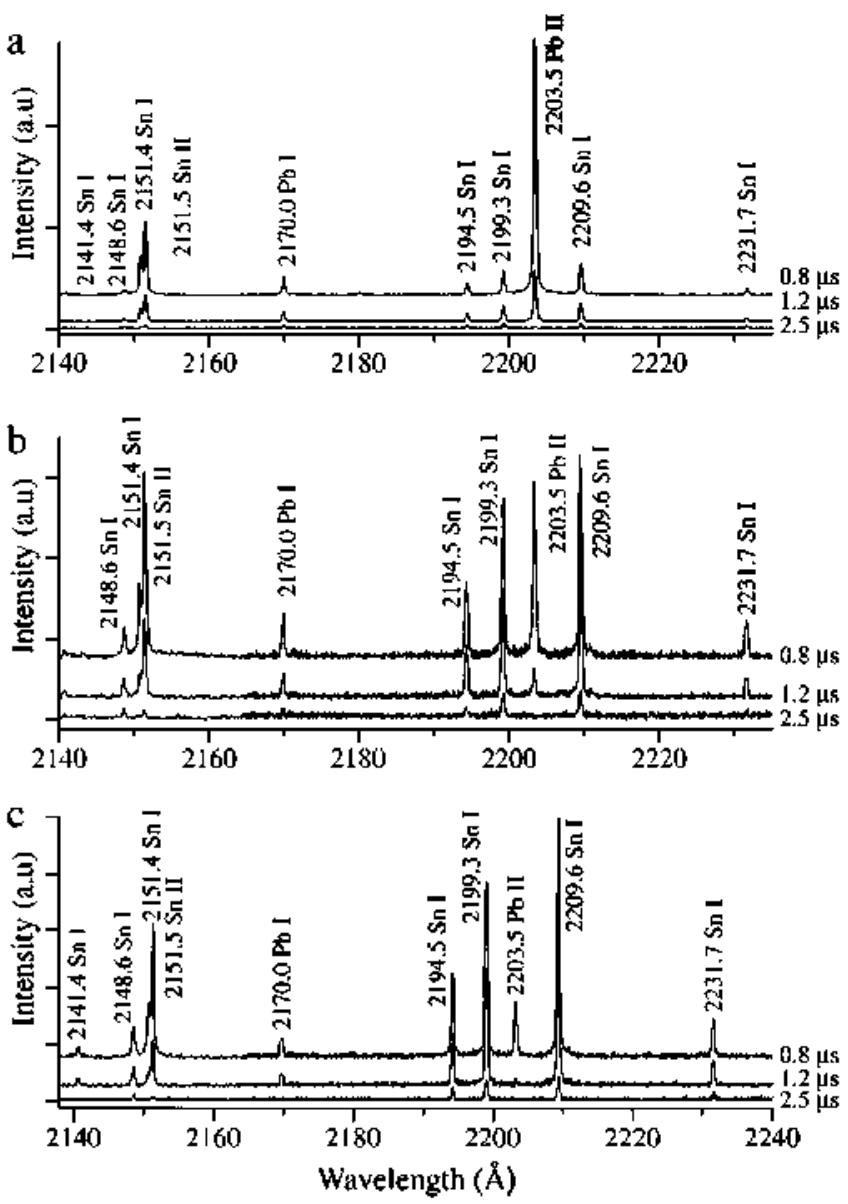

Fig. 3. ( $a, b$, and c). Various time-resolved emission spectral sections from laser-induced lead-tin plasma in vacuum: a) sample $75 \% \mathrm{~Pb}-25 \% \mathrm{Sn}$, b) sample $5 \% \mathrm{~Pb}-95 \% \mathrm{Sn}$ and c) sample $2 \% \mathrm{~Pb}-98 \% 5 \mathrm{~S}$.

$20 \%$ tin content. Therefore, this study leads us to measure the intensities of the $\mathrm{Sn} I$ lines, with the LIP, in vacuum, at 0.8 us after each laser light pulse and lead-tin (20\% Sn) target. An estimation of the absorption coefficient of all the lines studied (for $\mathrm{Sn} \mathrm{I,} \mathrm{Sn} \mathrm{II,} \mathrm{Pb} \mathrm{I,} \mathrm{and} \mathrm{Pb}$ II transitions), will be shown in a later discussion (Section 3.3), in order to verify that self-absorption was negligible.

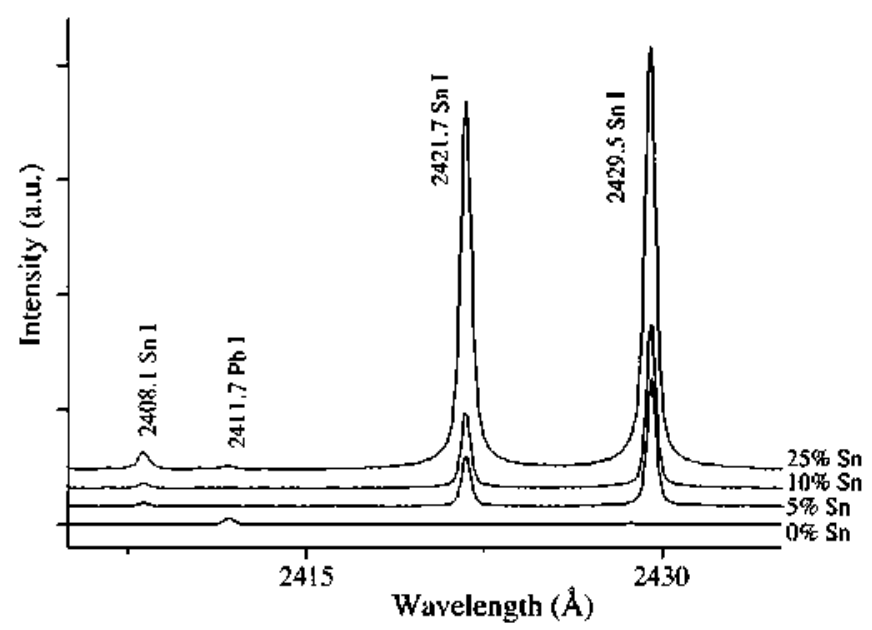

Fig. 4. A section of typical spectra for the 2380-2460 A range, in vacuum, for different tin concentrations at 0.8 us delay time. 

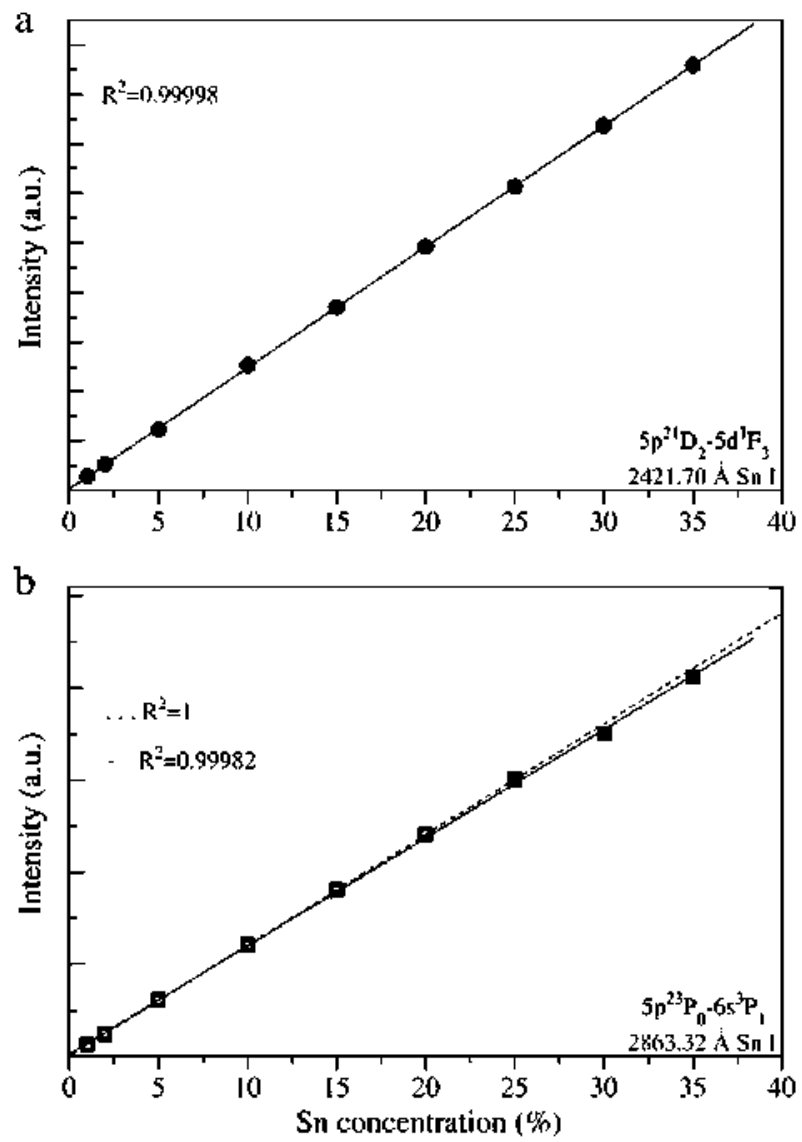

Fig. 5. (a and b). Two typical intensity versus sn concentration culves, for the $2421.7 \mathrm{~A}$ line and $2863.3 \mathrm{~A}$ resonance line of $\mathrm{sn}$ I $(0.8 \mu$ delay time at vacuum).

\section{Experimental results}

\subsection{Determination of the plasma temperature}

When LTE conditions can be applied, the population of the linked states follow a Boltzmann distribution, which can be used as a first approximation to determine the temperature $[55,56]$. Two criteria have been used to check the existence of LTE, based on the experimental measurement of the plasma temperature: a) the agreement between the Boltzmann distribution and the experimentally measured line intensities, which is reflected in the linearity of the Boltzmann plot besides by a unique temperature that describes the distribution of species in energy levels, the population of ionization stages, or the kinetic energy of electrons and heavier particles, and b) McWhirter's criterion, for the limit of the electron density, a necessary but not sufficient condition for LTE to hold.

As is well known in on optically thin plasma the relative intensities, $I_{i j}$ of the lines emitted from a given state of excitation can be used to calculate the electron temperature, if the $A_{i j}$ transition probabilities are known, by the expression:

$I_{i j}=\frac{A_{i j} g_{i}}{U(T)} N \exp \left(\frac{-E_{i}}{k T}\right)$

$\ln \left(\frac{I_{i j}}{A_{i j} g_{i}}\right)=\ln \left(\frac{N}{U(T)}\right)-\frac{E_{i}}{k T}$

for a transition from a higher state $i$ to a lower state $j, I_{i j}$ is the relative intensity, $E_{i}$ and $g_{i}$ are the energy and statistical weight of level $i, U(T)$ is the atomic species partition function, $N$ the total density of emitting atoms, $k$ the Boltzmann constant and $T$ the temperature. If we were to plot $\ln \left(I_{i j} / g_{i j} A_{i j}\right)$ vs. $E_{i}$, for lines of known transition probability (Boltzmann plot), the resulting straight line would have a slope $-1 / k T$, and therefore the temperature can be obtained without having to know the total density of atoms or the atomic species partition function. The energies of the different levels are those of Moore [57].

The plasma temperature has been determined by means of a Boltzmann plot for some lines of $\mathrm{Sn} I$. The electron temperature obtained was $13200 \pm 300 \mathrm{~K}$ for $\Delta E=2.13 \mathrm{eV}$, as can be seen in Fig. 6 . This was obtained, from the relative intensities $I_{\text {if }}$ required for applying this method, using a laser-induced plasma in this paper, and the transition probabilities were obtained from the reference (Penkin and Slavenas) [5], see Table 1, and the errors were estimated from the standard deviation of the slopes obtained in the least squares fittings. The uncertainties take into account are: a) the line profile fitting procedure $(\sim 1 \%)$, b) the maximum intensity stability $(\sim 2 \%)$ and $c$ ) the transition probabilities ( $7-30 \%$, depending on each line) [5].

As a confirmation of the LTE assumption we also obtain the plasma temperature from some lines of $\mathrm{Sn} \mathrm{II,} \mathrm{Pb} \mathrm{I} \mathrm{and} \mathrm{Pb}$ II, using the transition probabilities displayed in column four of Table 1, and which were obtained in our previous study $[36,47,49]$ respectively. With Sn II, an electron temperature of $13500 \pm 600 \mathrm{~K}$ for $\Delta E=3.58 \mathrm{eV}$ was found. With some lines of $\mathrm{Pb} \mathrm{I}$, an electron temperature of $13100 \pm 300 \mathrm{~K}$ for $\Delta E=2.22 \mathrm{eV}$ was obtained. With some lines of $\mathrm{Pb}$ II, an electron temperature of $13400 \pm 500 \mathrm{~K}$ for $\Delta E=3.24 \mathrm{eV}$ was obtained. These values are totally compatible and are close to $13200 \mathrm{~K}$. The linearity of the plots and the coincidence of the temperatures deduced from them supported the existence of LTE and assumption that the electron temperature was obtained in the measurements.

\subsection{Detemmination of the electron number density}

The Stark line broadening from collision of charged species is the primary mechanism influencing these emission spectra and instrumental line broadening. The Doppler broadening due to the random thermal motion of the emitter is estimated using the equation, based on the Maxwellian distribution law [55,58]. This contribution of the Doppler broadening is very small and can be safely ignored here.

The Voigt profile is the convolution of a Lorentzian curve and Gaussian curve; spectral lines are Lorentzian shaped. The Gaussian in the measured line profile is due to the spectroscopic apparatus. In this way convolution with the known instrumental profile can be taken into account, the spectral line intensity (area below profile) is obtained, the Lorentzian and Gaussian contributions to the full width at half maximum (FWHM) broadening can be separated, and lines with partial overlapping can be analysed.

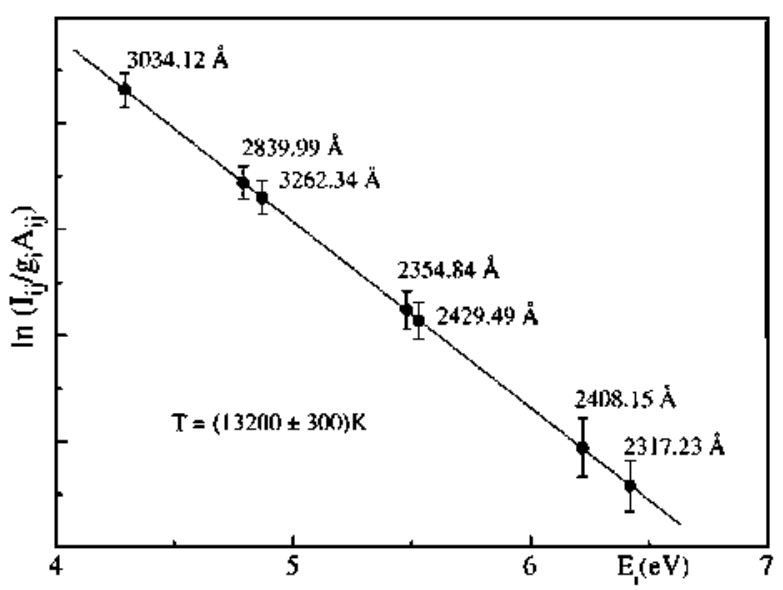

Fig. 6. Boltzmann plot for $5 n$ I spectral lines from laser-induced lead-tin (20\% tin purity) plasma, in vacuum, was recorded at $0.8 \mu$ delay time from laser pulse. 
Table 1

Parameters of Sn I, Sil II. Pb I and Pb II spectra lines used for election temperature determination (in vacuum, delay time of $0.8 \mu \mathrm{s},(20 \%) 5 n-(80 \%)$ Pb target).

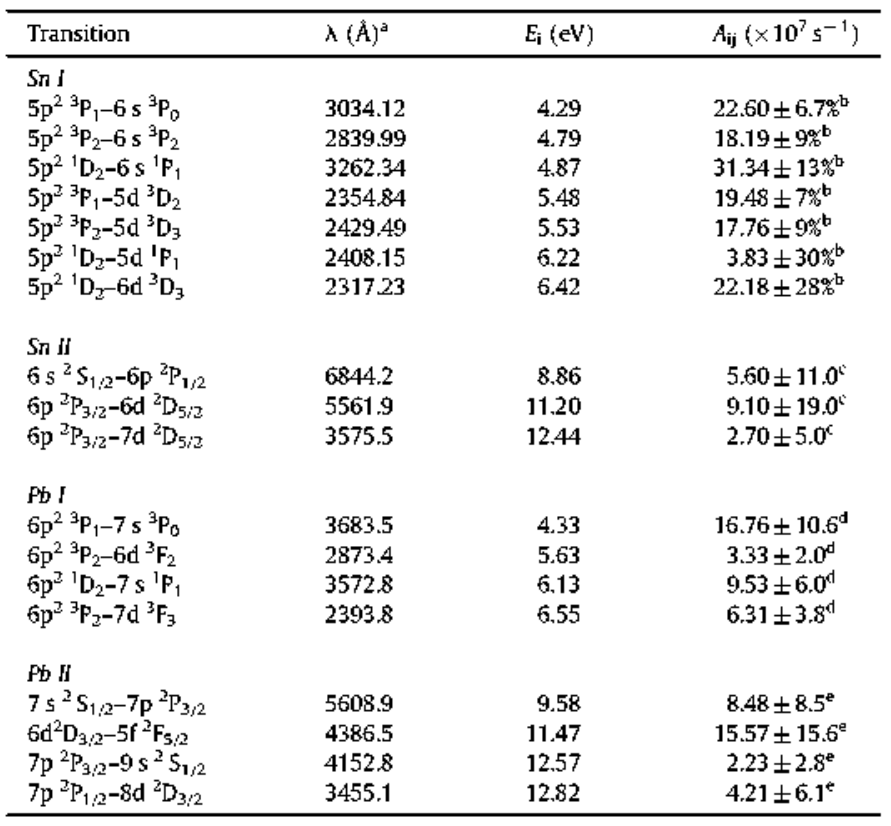

Moore [56],

benlein, Slavenas [5].

"Alonso-Medina Colon |36|.

Alonso-Medina et al. |49|.

e Alonso-Medina [47].

The electron density, $N_{\mathrm{e}}$, of the plasma under study is about $2 \times 10^{16} \mathrm{~cm}^{-3}$, and has been obtained by comparing the Stark broadenings for several transitions with those of others authors, see Table 2, using the expression by Befeki [56] and Milosavljevic and Poparic [59]:

$\omega=2 \omega_{\mathrm{p}}\left(\frac{N_{\mathrm{e}}}{10^{16}}\right)\left[1+1.75 A\left(\frac{N_{\mathrm{e}}}{10^{16}}\right)^{1 / 4}\left(1-1.2 N_{\mathrm{D}}^{-1 / 3}\right)\right]$

where $\omega$ (in $A$ ) is the FWHM of the transition considered and obtained at the density $N_{\mathrm{e}}$ expressed in $\mathrm{cm}^{-3}, \omega_{\mathrm{p}}$ is the Stark broadening

Table 2

Electron density of lead-tin ( $20 \%$ tin) plasma (vacuum, delay time of $0.8 \mu s$ ).

\begin{tabular}{|c|c|c|c|c|c|}
\hline $\begin{array}{l}\text { Transition } \\
\text { artay }\end{array}$ & Multiplet & $\lambda(A)^{a}$ & $\begin{array}{l}T \\
\left(10^{3} \mathrm{~K}\right)\end{array}$ & $\begin{array}{l}\omega_{\text {exp }}(\AA) \\
\left(N_{e}=10^{16} \mathrm{~cm}^{-3}\right)\end{array}$ & $\begin{array}{l}\mathrm{Ne}_{\mathrm{e}}\left(10^{16} \mathrm{~cm}^{-3}\right) \\
13200 \mathrm{~K}\end{array}$ \\
\hline $\begin{array}{l}S n i \\
5 p^{2}-6 s \\
5 p^{2}-6 s \\
5 p^{2}-5 d \\
5 p^{2}-6 d\end{array}$ & $\begin{array}{l}{ }^{3} P_{1}-{ }^{3} P_{0} \\
{ }^{3} P_{2}-{ }^{3} P_{2} \\
{ }^{3} P_{2}={ }^{3} D_{3} \\
{ }^{1} D_{2}-{ }^{3} D_{3}\end{array}$ & $\begin{array}{l}3034.12 \\
2839.99 \\
2429.49 \\
2317.20\end{array}$ & $\begin{array}{l}11.0 \\
11.0 \\
11.0 \\
11.0\end{array}$ & $\begin{array}{l}0.083 \pm 0.010^{b} \\
0.108 \pm 0.014^{b} \\
0.052 \pm 0.007^{b} \\
0.181 \pm 0.027^{b}\end{array}$ & $\begin{array}{l}1.99 \pm 12 \% \\
2.00 \pm 12 \% \\
1.98 \pm 13 \% \\
2.00 \pm 15 \%\end{array}$ \\
\hline $\begin{array}{l}\text { Sn if } \\
5 p-5 p^{2} \\
6 s-6 p\end{array}$ & $\begin{array}{l}{ }^{2} P_{3 / 2}-{ }^{4} P_{1 / 2} \\
{ }^{2} S_{1 / 2}-P_{1 / 2}\end{array}$ & $\begin{array}{l}2368.30 \\
6844.00\end{array}$ & $\begin{array}{l}11.0 \\
11.0\end{array}$ & $\begin{array}{l}0.049 \pm 0.007^{\mathrm{b}} \\
0.42 \pm 0.05^{\mathrm{b}}\end{array}$ & $\begin{array}{l}2.00 \pm 15 \% \\
2.10 \pm 15 \%\end{array}$ \\
\hline $\begin{array}{l}P b I \\
6 p^{2}-7 s \\
6 p^{2}-7 s\end{array}$ & $\begin{array}{l}{ }^{3} \mathrm{P}_{1}-{ }^{3} \mathrm{P}_{1} \\
{ }^{1} \mathrm{D}_{2}-{ }^{1} \mathrm{P}_{1}\end{array}$ & $\begin{array}{l}3639.50 \\
3572.80\end{array}$ & $\begin{array}{l}11.2 \\
11.2\end{array}$ & $\begin{array}{l}0.153 \pm 0.015^{\circ} \\
0.072 \pm 0.007^{c}\end{array}$ & $\begin{array}{l}1.99 \pm 12 \% \\
1.98 \pm 12 \%\end{array}$ \\
\hline $\begin{array}{l}P b I \\
6 \mathrm{p}-7 s \\
6 \mathrm{~d}-5 \mathrm{f}\end{array}$ & $\begin{array}{l}{ }^{2} \mathrm{P}_{3 / 2} \mathbf{-}^{2} \mathrm{~S}_{1 / 2} \\
{ }^{2} \mathrm{D}_{3 / 2}-{ }^{2} \mathrm{~F}_{5 / 2}\end{array}$ & $\begin{array}{l}2203.5 \\
4386.50\end{array}$ & $\begin{array}{l}11.3 \\
11.3\end{array}$ & $\begin{array}{l}0.11 \pm 0.01^{\alpha} \\
0.13 \pm 0.02^{\alpha}\end{array}$ & $\begin{array}{l}2.00 \pm 13 \% \\
2.02 \pm 15 \%\end{array}$ \\
\hline
\end{tabular}

Moore [56],

Alonso-Medina, Colón |40|.

" Alonso-Medina. [52].

¿ Colón, Alonso-Medina [50]. parameter, $A$ is the ion broadening parameter, and $N_{D}$ is the number of particles in the Debye sphere, which must be in excess of the lower limit $N_{D}=2$ of the Debye approximation for correlation effects, Wolf [60]. For the electron densities present in this study, the quasi-static ion broadening, take into account in the second term in the expression (2), is only approximately $5 \%$ of total width. In our measurements we have assumed that $\mathrm{A}$ is negligible (Konjevic [61]).

We have selected lines with published broadening Stark widths that present small uncertainties: $3034.12 \AA, 2839.99 \AA, 2429.49 \AA$ and $2317.20 \AA$ Sn I spectral lines obtained in our previous study, for a temperature of $11000 \mathrm{~K}$ and $N_{e}=1.1 \times 10^{16} \mathrm{~cm}^{-3}$. Alonso-Medina and Colón [40]. The electron density was, $(1.99 \pm 0.24) \times 10^{16} \mathrm{~cm}^{-3}$, $(2.00 \pm 0.24) \times 10^{16} \mathrm{~cm}^{-3},(1.98 \pm 0.26) \times 10^{16} \mathrm{~cm}^{-3}$ and $(2.00 \pm$ $0.30) \times 10^{16} \mathrm{~cm}^{-3}$ respectively. Also, we have selected with published broadening Stark for $\mathrm{Sn} \mathrm{II,} \mathrm{Pb} \mathrm{I} \mathrm{and} \mathrm{Pb} \mathrm{II,} \mathrm{see} \mathrm{Table} \mathrm{2.} \mathrm{The} \mathrm{error} \mathrm{of}$ the determined electron density comprises the error of the Stark width measurement and the reference Stark width [40,50,52]. The values of the electron densities from very different spectrum lines are in good agreement. These values are totally compatible and are close to $2 \times 10^{16} \mathrm{~cm}^{-3}$.

In addition to the consistency of $\mathrm{Sn}$ and $\mathrm{Pb}$ temperatures, in order to support the LTE assumption, we used the McWhirter's criterion [62]

$N_{\mathrm{e}}\left(\mathrm{cm}^{-3}\right) \geq 1.6 \times 10^{12} \sqrt{T}(\Delta E)^{3}$

where $\Delta E$, (in eV), is the energy difference between the upper and lower strongly radiatively coupled states, and $T$, (in $\mathrm{K}$ ), the temperature and $\mathrm{N}_{\mathrm{e}}$ the lower limit of the electron density necessary to maintain the populations of the energy levels at $10 \%$ of the LTE by collision, in competition with the radiative processes.

Using the values obtained for the Sn I lines, the critical $N_{e}$ is $1.78 \times 10^{15} \mathrm{~cm}^{-3}$, using the values obtained for the Sn II lines, the critical $\mathrm{N}_{e}$ is $8.43 \times 10^{15} \mathrm{~cm}^{-3}$, using the values obtained for $\mathrm{Pb}$ [ lines, the critical $N_{e}$ is $2.00 \times 10^{15} \mathrm{~cm}^{-3}$, and using the values obtained for $\mathrm{Pb}$ Il lines, the critical $\mathrm{N}_{\mathrm{e}}$ is $6.30 \times 10^{15} \mathrm{~cm}^{-3}$.

The values given for $N_{e}$ and $T$ correspond to the centre of the plasma. To determine the change of these parameters in different regions of the plasma, we have obtained their values at different points using various lines of $\mathrm{Sn} \mathrm{I}$, and the result being that there is homogeneity for $N_{\mathrm{e}}$ and T.

\subsection{Self-adsorption analysis}

With the aforementioned values of $N_{\mathrm{e}}$ and $T$ we can calculate the absorption coefficient for the studied lines, using the following equation [63], expressed in $\mathrm{m}^{-1}$ :

$k_{\omega}=\frac{\pi e^{2}}{2 \varepsilon_{0} m c} f_{i k} N_{i}\left[1-\frac{N_{k} g_{i}}{N_{i} g_{k}}\right] \mathbf{g}(\omega)$

where $f_{i k}$ is the oscillator strength (absorption), $g_{i}$ and $g_{j}$ are statistical weight of state and $\mathrm{g}(\omega)$ is the normalized profile of the line. In the maximum, $\omega=0$, and for a Lorentz profile, $g(0)=2 / \pi \Gamma$, where $\Gamma$ is the FWHM of the line. $N_{k}$ and $N_{i}$ are the population density of the lowerlevel energy and upper-level energy, respectively, and estimated to be approximately equal to the electron density, this being an upper limit. A line may be considered optically thin if $k_{00} L \leq 0.05$ [64], that the value of the optical depth $k_{(s)} L$ in this paper is not in excess of 0.02 , for example 0.018 in $2863.3 \AA$ resonance line. In the lines studied in this paper, selfadsorption was negligible (the value of $L$ having been $2 \mathrm{~mm}$ ).

\subsection{Transition probabilities of Sn I}

For homogeneous and optically thin plasma in LTE at the temperature $T$, the transition probabilities have been determined from 
Table 3

Sn I transition probabilities obtained from Boltzmann plot (in vacuum, delay time of $0.8 \mu \mathrm{s},(20 \%) \mathrm{sn}-(80 \%) \mathrm{Pb}$ target $)$. Comparison of the obtained values witl published ones.

\begin{tabular}{|c|c|c|c|c|c|c|}
\hline \multirow[t]{2}{*}{ Transition levels } & \multirow[t]{2}{*}{$\lambda(A)$} & \multicolumn{5}{|c|}{ Absolute transition probabilities $\left(\times 10^{7} \mathrm{~s}^{-1}\right)$} \\
\hline & & \multicolumn{2}{|l|}{ This work } & \multicolumn{3}{|c|}{ Other works } \\
\hline & & & & & & NIST \\
\hline $6 \mathrm{~s}^{3} \mathrm{P}_{0} \rightarrow 5 \mathrm{p}^{2}{ }^{3} \mathrm{P}_{1}$ & 3034.1 & $21.1 \pm 1.9$ & $22.6 \mathrm{~A}^{\mathrm{b}}$ & $15.3^{i}$ & $23 \mathrm{C}^{\mathbf{j}}$ & 20.0 \\
\hline $6 \mathrm{~s}^{3} \mathrm{P}_{1} \rightarrow 5 \mathrm{p}^{2}{ }^{3} \mathrm{P}_{0}$ & 28642 & $6.2 \pm 0.7$ & $6.2 \mathrm{~A}^{\mathrm{b}}$ & $5.8^{\mathrm{i}}$ & & 5.4 \\
\hline $5 p^{23} p_{1}$ & 3010.0 & $4.7 \pm 0.5$ & $4.3 \mathrm{~A}^{\mathrm{b}}$ & $3.6^{\mathbf{i}}$ & & 3.8 \\
\hline $5 p^{2}{ }^{3} P_{2}$ & 3175.9 & $11.2 \pm 1.3$ & $11.6 \mathrm{~A}^{\mathrm{b}}$ & $8.3^{\prime}$ & & 10.0 \\
\hline $5 p^{2} D_{2}$ & 3802.1 & $3.0 \pm 0.4$ & $3.3 \mathrm{~A}^{\mathrm{b}}$ & $3.7^{1}$ & & 2.8 \\
\hline $5 p^{2} s_{0}$ & 5633.3 & $0.21 \pm 0.03$ & $0.24 D^{k}$ & & & 0.24 \\
\hline $6 \mathrm{~s}^{3} \mathrm{P}_{2} \rightarrow 5 \mathrm{p}^{2}{ }^{3} \mathrm{P}_{1}$ & 2707.3 & $7.1 \pm 0.6$ & $7.3 \mathrm{~A}^{\mathrm{b}}$ & $5.0^{\mathrm{i}}$ & $32 \mathrm{C}^{\mathrm{j}}$ & 6.6 \\
\hline $5 \mathrm{p}^{2}{ }^{3} \mathrm{p}_{2}$ & 2840.8 & $16.0 \pm 1.6$ & $182 \mathrm{~A}^{\mathrm{b}}$ & $16.3^{i}$ & $16 C^{j}$ & 17.0 \\
\hline $5 \mathrm{p}^{2} \mathrm{D}_{2}$ & 3331.6 & $2.1 \pm 0.2$ & $2.4 C^{b}$ & $1.6^{i}$ & $1.7 \mathrm{C}^{\mathrm{j}}$ & 2.0 \\
\hline $6 \mathrm{~s}^{1} \mathrm{P}_{1} \rightarrow 5 \mathrm{p}^{2}{ }^{3} \mathrm{P}_{0}$ & 2547.3 & $2.3 \pm 0.2$ & $2.5 \mathrm{~A}^{\mathrm{b}}$ & $2.9^{\mathbf{i}}$ & $3.0 \mathrm{C}^{\mathrm{j}}$ & 2.1 \\
\hline $5 p^{23} p_{1}$ & 2662.0 & $1.2 \pm 0.1$ & $1.3 \mathrm{~A}^{\mathrm{b}}$ & $1.6^{\prime}$ & $1.90^{\mathrm{i}}$ & 1.1 \\
\hline $5 p^{2}{ }^{3} p_{1}$ & 2791.0 & $0.012 \pm 0.002$ & & & & \\
\hline $5 p^{2} D_{2}$ & 3263.3 & $27.3 \pm 2.8$ & $31.3 \mathrm{~B}^{\mathrm{b}}$ & $33.6^{\mathrm{i}}$ & $190^{\mathrm{j}}$ & 27.0 \\
\hline $5 p^{2} s_{0}$ & 4526.0 & $2.1 \pm 0.2$ & & & $2.6 C^{j}$ & 2.6 \\
\hline $7 \mathrm{~s}^{3} \mathrm{P}_{1} \rightarrow 5 \mathrm{p}^{2}{ }^{3} \mathrm{P}_{0}$ & 2073.7 & $0.45 \pm 0.06$ & & & & 0.36 \\
\hline $5 p^{2}{ }^{3} p_{2}$ & 22322 & $0.93 \pm 0.09$ & & & & \\
\hline $5 p^{2} D_{2}$ & 2524.7 & $0.74 \pm 0.07$ & & & $0.74 \mathrm{C}^{\mathrm{j}}$ & 0.74 \\
\hline $5 p^{2} s_{0}$ & 3219.6 & $0.33 \pm 0.03$ & & & $0.47 \mathrm{C}^{\mathrm{j}}$ & 0.47 \\
\hline $7 \mathrm{~s}^{3} \mathrm{P}_{2} \rightarrow 5 \mathrm{p}^{2}{ }^{3} \mathrm{P}_{1}$ & 1971.4 & $0.36 \pm 0.04$ & & & & \\
\hline $5 \mathrm{p}^{2}{ }^{3} \mathrm{p}_{2}$ & 2041.3 & $0.48 \pm 0.05$ & & & & \\
\hline $5 \mathrm{p}^{2} \mathrm{D}_{2}$ & 2283.0 & $0.15 \pm 0.02$ & & & & \\
\hline $7 \mathrm{~s}^{1} \mathrm{P}_{1} \rightarrow 5 \mathrm{p}^{2}{ }^{3} \mathrm{P}_{1}$ & 19602 & $0.063 \pm 0.007$ & & & & \\
\hline $5 p^{2} P_{2}$ & 2029.2 & $0.094 \pm 0.02$ & & & & \\
\hline $5 p^{2} D_{2}$ & 2267.9 & $1.9 \pm 0.2$ & & & & \\
\hline $5 p^{2} S_{0}$ & 2813.4 & $2.1 \pm 0.2$ & & & $2.3 \mathrm{C}^{\mathrm{i}}$ & 2.3 \\
\hline $8 s^{3} p_{1} \rightarrow 5 p^{2}{ }^{3} p_{2}$ & 2016.4 & $0.19 \pm 0.02$ & & & & \\
\hline $5 \mathrm{p}^{2} \mathrm{I}_{2}$ & 2251.9 & $0.86 \pm 0.09$ & & & & \\
\hline $5 p^{2}{ }^{1} s_{0}$ & 2788.8 & $0.85 \pm 0.08$ & & & $1.4 \mathrm{C}^{\mathrm{j}}$ & 1.4 \\
\hline $8 \mathrm{~s}^{1} \mathrm{P}_{1} \rightarrow 5 \mathrm{p}^{2} \mathrm{~S}_{0}$ & 2492.5 & $0.34 \pm 0.04$ & & & $1.7 \mathrm{C}^{\mathrm{j}}$ & 0.17 \\
\hline $5 p^{35} S_{2} \rightarrow 5 p^{3} P_{2}$ & 2762.6 & $0.036 \pm 0.003$ & $0.043 \mathrm{~A}^{\mathrm{b}}$ & & $0.059 \mathrm{C}^{\mathrm{j}}$ & 0.037 \\
\hline $5 p^{2} \mathrm{I}_{2}$ & 3224.5 & $0.011 \pm 0.001$ & & & $0.012 \mathrm{C}^{\mathrm{j}}$ & \\
\hline $7 \mathrm{p}^{3} \mathrm{P}_{0} \rightarrow 6 \mathrm{~s}^{3} \mathrm{P}_{1}$ & 6075.1 & $0.48 \pm 0.05$ & $0.63 \mathrm{D}^{\mathrm{k}}$ & & & 0.63 \\
\hline $7 p^{3} p_{1} \rightarrow 6 s^{3} p_{0}$ & 6205.4 & $0.053 \pm 0.005$ & $0.079 D^{k}$ & & & \\
\hline $6 \mathrm{~s}^{3} \mathrm{P}_{1}$ & 6312.5 & $0.09 \pm 0.01$ & $0.15 D^{k}$ & & & \\
\hline $7 \mathrm{p}^{3} \mathrm{P}_{2} \rightarrow 6 \mathrm{~s}^{3} \mathrm{P}_{2}$ & 6039.3 & $0.34 \pm 0.03$ & $0.500^{k}$ & & & 0.50 \\
\hline $7 \mathrm{p}^{3} \mathrm{D}_{1} \rightarrow 6 \mathrm{~s}^{3} \mathrm{P}_{0}$ & 6070.7 & $0.33 \pm 0.02$ & $0.46 D^{k}$ & & & 0.46 \\
\hline $6 s^{3} p_{1}$ & 6173.2 & $0.37 \pm 0.04$ & $0.49 D^{k}$ & & & 0.42 \\
\hline $7 p^{3} D_{2} \rightarrow 6 s^{3} p_{1}$ & 6151.3 & $0.21 \pm 0.02$ & $0.590^{k}$ & & & \\
\hline $7 \mathrm{p}^{3} \mathrm{D}_{3} \rightarrow 6 \mathrm{~s}^{3} \mathrm{P}_{2}$ & 6056.5 & $0.23 \pm 0.02$ & $0.32 D^{k}$ & & & \\
\hline $7 \mathrm{p}^{1} \mathrm{~S}_{0} \rightarrow 6 \mathrm{~s}^{3} \mathrm{P}_{1}$ & 5763.3 & $0.038 \pm 0.004$ & $0.048 \mathrm{D}^{k}$ & & & \\
\hline $7 \mathrm{p}^{1} \mathrm{P}_{1} \rightarrow 6 \mathrm{~s}^{1} \mathrm{P}_{1}$ & 6356.1 & $0.062 \pm 0.007$ & $0.084 D^{k}$ & & & \\
\hline $7 \mathrm{p}^{3} \mathrm{~s}_{1} \rightarrow 6 \mathrm{~s}^{3} \mathrm{P}_{2}$ & 5971.9 & $0.60 \pm 0.06$ & $0.95 D^{k}$ & & & 0.96 \\
\hline $7 \mathrm{p}^{1} \mathrm{D}_{2} \rightarrow 6 \mathrm{~s}^{3} \mathrm{P}_{2}$ & 5927.0 & $0.17 \pm 0.03$ & $0.22 D^{k}$ & & & \\
\hline $6 s^{1} p_{1}$ & 6156.3 & $0.90 \pm 0.09$ & $1.11 D^{k}$ & & & \\
\hline $5 d^{3} F_{2} \rightarrow 5 p^{2}{ }^{3} F_{1}$ & 2381.4 & $0.36 \pm 0.04$ & $0.36 \mathrm{~B}^{\mathrm{k}}$ & & $0.230^{i}$ & 0.31 \\
\hline $5 p^{23} P_{2}$ & 2484.1 & $2.2 \pm 0.2$ & $2.3 \mathrm{~A}^{\mathrm{b}}$ & & $2.3 \mathrm{D}^{\mathrm{j}}$ & 2.1 \\
\hline $5 \mathrm{p}^{2} \mathrm{D}_{2}$ & 2851.4 & $2.7 \pm 0.3$ & $3.8 \mathrm{c}^{\mathrm{b}}$ & & $2.9 \mathrm{C}^{\mathrm{j}}$ & 3.3 \\
\hline $5 d^{3} F_{3} \rightarrow 5 p^{2}{ }^{3} P_{2}$ & 2269.6 & $8.9 \pm 0.9$ & $13.9 \mathrm{~B}^{\mathrm{b}}$ & & & 12.0 \\
\hline $5 p^{2} D_{2}$ & 2572.3 & $4.0 \pm 0.4$ & $5.1 \mathrm{~B}^{\mathrm{b}}$ & & $2.9 C^{j}$ & 4.5 \\
\hline $5 \mathrm{~d}^{3} \mathrm{D}_{1} \rightarrow 5 \mathrm{p}^{2}{ }^{3} \mathrm{P}_{0}$ & 2246.7 & $11.4 \pm 1.1$ & $18.1 \mathrm{~A}^{\mathrm{b}}$ & & & 16.0 \\
\hline $5 p^{23} P_{1}$ & 2335.5 & $4.6 \pm 0.4$ & $7.7 \mathrm{~A}^{\mathrm{b}}$ & & $6.7 \mathrm{D}^{\mathrm{j}}$ & 6.6 \\
\hline $5 p^{23} p_{2}$ & 2434.2 & $0.091 \pm 0.009$ & & & $0.08 \mathrm{D}^{\mathrm{i}}$ & 0.08 \\
\hline $5 \mathrm{p}^{2} \mathrm{I}_{2}$ & 2785.8 & $0.72 \pm 0.08$ & & & $1.4 \mathrm{C}^{\mathrm{i}}$ & 1.4 \\
\hline $5 \mathrm{p}^{2} \mathrm{~S}_{0}$ & 3656.8 & $0.40 \pm 0.04$ & & & $0.41 \mathrm{c}^{\mathrm{j}}$ & 0.41 \\
\hline $5 d^{3} D_{2} \rightarrow 5 p^{2}{ }^{3} P_{1}$ & 2355.6 & $14.4 \pm 1.1$ & $19.5 \mathrm{~A}^{\mathrm{b}}$ & & $21 \mathrm{D}^{\mathrm{j}}$ & 17.0 \\
\hline $5 p^{2}{ }^{3} p_{2}$ & 2456.0 & $0.13 \pm 0.01$ & $0.14 \mathrm{~B}^{\mathrm{b}}$ & & $0.110^{j}$ & 0.11 \\
\hline $5 p^{2} D_{2}$ & 2814.4 & $0.92 \pm 0.09$ & & & $1.2 \mathrm{C}^{\mathrm{j}}$ & 1.2 \\
\hline $5 d^{3} \mathrm{D}_{3} \rightarrow 5 \mathrm{p}^{2}{ }^{3} \mathrm{P}_{2}$ & 2430.2 & $12.5 \pm 1.2$ & $17 \mathrm{~A}^{\mathrm{b}}$ & & $17 \mathrm{D}^{\mathrm{j}}$ & 15.0 \\
\hline $5 \mathrm{p}^{2} \mathrm{D}_{2}$ & 2780.6 & $1.2 \pm 0.1$ & $2.2 \mathrm{~B}^{\mathrm{b}}$ & & $1.50^{\mathrm{i}}$ & 1.8 \\
\hline $5 \mathrm{~d}^{1} \mathrm{D}_{2} \rightarrow 5 \mathrm{p}^{2}{ }^{3} \mathrm{P}_{1}$ & 2200.0 & $2.3 \pm 0.3$ & & & & \\
\hline $5 \mathrm{p}^{2}{ }^{3} \mathrm{p}_{2}$ & 2287.4 & $2.6 \pm 0.2$ & $3.6 \mathrm{~B}^{\mathrm{b}}$ & & & 3.1 \\
\hline $5 p^{2} D_{2}$ & 25952 & $3.6 \pm 0.4$ & $3.4 \mathrm{~B}^{\mathrm{b}}$ & & $1.8 \mathrm{C}^{\mathrm{j}}$ & 3.0 \\
\hline $5 d^{3} P_{2} \rightarrow 5 p^{2}{ }^{3} P_{2}$ & 2210.3 & $4.0 \pm 0.4$ & & & & 5.6 \\
\hline $5 p^{2} \mathrm{D}_{2}$ & 2496.5 & $5.6 \pm 0.7$ & $7.2 \mathrm{c}^{\mathrm{b}}$ & & $3.7 \mathrm{D}^{\mathrm{j}}$ & 6.2 \\
\hline $5 d^{3} \mathrm{P}_{1} \rightarrow 5 \mathrm{p}^{2}{ }^{3} \mathrm{P}_{0}$ & 2041.6 & $0.13 \pm 0.02$ & & & & \\
\hline $5 p^{23} p_{1}$ & 2114.6 & $1.7 \pm 0.2$ & & & & \\
\hline $5 p^{2}{ }^{3} p_{2}$ & 21952 & $2.6 \pm 0.3$ & & & & \\
\hline $5 p^{2} D_{2}$ & 24772 & $0.14 \pm 0.02$ & & & $0.11 D^{j}$ & 0.11 \\
\hline $5 p^{2} S_{0}$ & 3142.7 & $1.1 \pm 0.1$ & & & $1.9 C^{j}$ & 1.9 \\
\hline $5 d^{3} P_{0} \rightarrow 5 p^{2}{ }^{3} P_{1}$ & 2020.7 & $0.15 \pm 0.02$ & & & & \\
\hline $5 d^{\prime} F_{3} \rightarrow 5 p^{2}{ }^{3} P_{2}$ & 2152.1 & $1.0 \pm 0.1$ & & & & \\
\hline
\end{tabular}

Table 3 (continued)

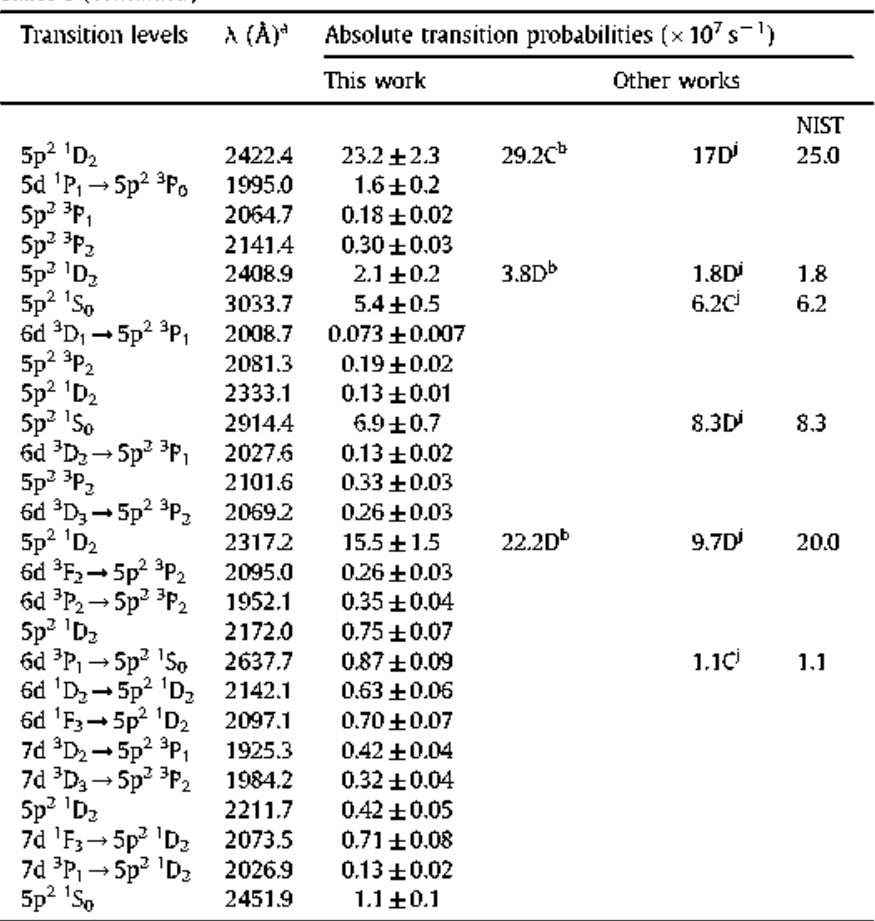

Estimated uncertainty: $A \leq 10 \%, 10 \% \leq B \leq 20 \%, 20 \% \leq C \leq 25 \%, 25 \% \leq D \leq 50 \%$.

The NIST atomic spectra collection.

ttp:/physics.nistgov/PhysRefData/ASD/lines.form.html.

Moore [56].

b Penkin, Slavenas |5|.

i Lotrian et al. [9].

j Wujec, Musielokr | 10|

k Wujec, Weniger [11].

Boltzmann plot, expression (1). Transition probabilities obtained from this method for 97 spectral lines of $\mathrm{Sn}$ I with wavelengths in the range of $1900-6200 \AA$, are displayed in column three of Table 3 , while columns one and two give the transitions and corresponding wavelengths respectively. The remaining columns give the experimental transition probability values to be found in the bibliography. The uncertainties take into account are: the line profile fitting procedure (1\%), the maximum intensity stability (2\%), the selfabsorption correction line егrors $(<1 \%)$ and dispersion of temperatures obtained within the series of different diagnostics (7\%). The majority of the results obtained in this paper are in agreement with the results of [5], [9] and [10], within the measurement error limit. The $A_{\mathrm{ij}}$-values of Wujec and Weniger [11] are measured with errors of about $40 \%$.

Transition probabilities can be determined either from relative intensities measurements or branching ratio method. Branching ratios method is suitable when studying transition probabilities of lines within a multiplet. In this method, all transitions from the same level are considered. Using the known upper state lifetimes $\tau_{i}$ and the branching ratios $R_{\mathrm{ij}}$, transition probabilities $A_{\mathrm{ij}}$ are deduced

$R_{i j}=\frac{l_{i j}}{\sum_{i j}}=\frac{A_{i j}}{\sum_{i} A_{i j}}$ and $T_{i}=\frac{1}{\sum_{i} A_{i j}}$ then $A_{i j}=\frac{R_{i j}}{\tau_{i}}$

Where $I_{i j}$ are the relative intensities obtained in this paper.

Transition probabilities of lines with origin in the $6 s^{3} P_{1}, 6 s^{3} P_{2}$ $6 s^{1} \mathrm{P}_{1}, 5 d{ }^{3} \mathrm{~F}_{2}, 5 d{ }^{3} \mathrm{~F}_{3}, 5 \mathrm{~d}{ }^{3} \mathrm{D}_{1}, 5 d{ }^{3} \mathrm{D}_{2}$ and $5 d{ }^{3} \mathrm{D}_{3}$ states of $\mathrm{Sn} \mathrm{I}$, are calculated from available radiative lifetime, $\tau(\mathrm{ns})$, in literature $[42,44,46]$ and branching ratio measurements of lines arising from these levels are displayed in columns three, four and five of Table 4 . The uncertainties take into account are: the line profile ficting procedure (1\%), the maximum intensity stability (2\%), the self-absorption correction 
Table 4

Absolute nansition probabilities of some lines of $5 n$ I multiplets obtained with branching ratio technique (in vacuum, delay time of $0.8 \mu 5$, (20\%) $5 n-(80 \%$ ) Pb target).

\begin{tabular}{|c|c|c|c|c|}
\hline Transition Levels & $A(\hat{A})^{a}$ & \multicolumn{3}{|c|}{ Absolute transition probabilities $\left(\times 10^{7} \mathrm{~s}^{-1}\right)$} \\
\hline $\begin{array}{l}6 s^{3} \mathrm{P}_{1} \rightarrow 5 \mathrm{p}^{2}{ }^{3} \mathrm{P}_{0} \\
5 \mathrm{p}^{2}{ }^{3} \mathrm{p}_{1} \\
5 \mathrm{p}^{2}{ }^{3} \mathrm{p}_{2} \\
5 \mathrm{p}^{2}{ }^{1} \mathrm{D}_{2} \\
5 \mathrm{p}^{2}{ }^{1} \mathrm{~s}_{0}\end{array}$ & $\begin{array}{l}2864.2 \\
3010.0 \\
3175.9 \\
3802.1 \\
5633.3\end{array}$ & $\begin{array}{l}\tau=5.0 \pm 0.5 \mathrm{~ns}^{\mathrm{k}} \\
5.0 \pm 0.6 \\
3.6 \pm 0.5 \\
8.9 \pm 1.1 \\
2.4 \pm 0.3 \\
0.15 \pm 0.02\end{array}$ & $\begin{array}{l}\tau=4.75 \pm 0.18 \mathrm{~ns} \\
5.3 \pm 0.4 \\
3.8 \pm 0.3 \\
9.4 \pm 0.8 \\
2.5 \pm 0.2 \\
0.16 \pm 0.01\end{array}$ & $\begin{array}{l}\tau=6.0 \pm 0.9 n s^{m} \\
4.2 \pm 0.6 \\
3.0 \pm 0.4 \\
7.4 \pm 1.1 \\
2.0 \pm 0.3 \\
0.12 \pm 0.02\end{array}$ \\
\hline $\begin{array}{l}6 s^{3} \mathrm{P}_{2} \rightarrow 5 \mathrm{p}^{2}{ }^{3} \mathrm{P}_{1} \\
5 \mathrm{p}^{2}{ }^{3} \mathrm{P}_{2} \\
5 \mathrm{p}^{2}{ }^{1} \mathrm{D}_{2}\end{array}$ & $\begin{array}{l}2707.3 \\
2840.8 \\
3331.6\end{array}$ & $\begin{array}{l}\tau=4.6 \pm 0.5 \mathrm{~ns}^{\mathrm{k}} \\
6.1 \pm 0.8 \\
13.8 \pm 1.8 \\
1.8 \pm 0.2\end{array}$ & $\begin{array}{l}\tau=4.25 \pm 0.23 \mathrm{~ns}^{1} \\
6.6 \pm 0.6 \\
15.0 \pm 1.3 \\
1.9 \pm 0.2\end{array}$ & $\begin{array}{l}\tau=4.7 \pm 0.7 n s^{m} \\
6.0 \pm 1.0 \\
13.5 \pm 2.2 \\
1.7 \pm 0.3\end{array}$ \\
\hline $\begin{array}{l}6 s{ }^{1} \mathrm{P}_{1} \rightarrow 5 p^{2}{ }^{3} \mathrm{P}_{0} \\
5 p^{2}{ }^{3} \mathrm{P}_{1} \\
5 p^{2}{ }^{3} \mathrm{P}_{1} \\
5 p^{2}{ }^{1} \mathrm{D}_{2} \\
5 \mathrm{p}^{2}{ }^{1} \mathrm{~s}_{0}\end{array}$ & $\begin{array}{l}2547.3 \\
2662.0 \\
2791.0 \\
3263.3 \\
4526.0\end{array}$ & $\begin{array}{l}\tau=4.4 \pm 0.5 \mathrm{~ns}^{\mathrm{k}} \\
1.7 \pm 0.2 \\
1.3 \pm 0.2 \\
0.012 \pm 0.002 \\
18.0 \pm 2.3 \\
1.6 \pm 0.2\end{array}$ & $\begin{array}{l}\tau=4.11 \pm 0.2211 \mathrm{~s}^{\prime} \\
1.8 \pm 0.1 \\
1.4 \pm 0.1 \\
0.012 \pm 0.004 \\
19.3 \pm 1.5 \\
1.8 \pm 0.1\end{array}$ & \\
\hline $\begin{array}{l}5 d{ }^{3} \mathrm{~F}_{2} \rightarrow 5 \mathrm{p}^{2}{ }^{3} \mathrm{p}_{1} \\
5 \mathrm{p}^{2}{ }^{3} \mathrm{P}_{2} \\
5 \mathrm{p}^{2}{ }^{1} \mathrm{D}_{2}\end{array}$ & $\begin{array}{l}2381.4 \\
2484.1 \\
2851.4\end{array}$ & $\begin{array}{l}\tau=24 \pm 2 n s^{k} \\
0.31 \pm 0.03 \\
1.9 \pm 0.02 \\
2.0 \pm 0.02\end{array}$ & & \\
\hline $\begin{array}{l}5 d^{3} F_{3} \rightarrow 5 p^{2}{ }^{3} P_{2} \\
5 p^{2}{ }^{1} D_{2}\end{array}$ & $\begin{array}{l}2269.6 \\
2572.3\end{array}$ & $\begin{array}{l}\tau=6.0 \pm 0.6 \mathrm{~ns}^{\mathrm{k}} \\
11.5 \pm 1.5 \\
5.2 \pm 0.7\end{array}$ & & \\
\hline $\begin{array}{l}5 d^{3} \mathrm{D}_{1} \rightarrow 5 \mathrm{p}^{2}{ }^{3} \mathrm{P}_{0} \\
5 \mathrm{p}^{2}{ }^{3} \mathrm{p}_{1} \\
5 \mathrm{p}^{2}{ }^{3} \mathrm{p}_{2} \\
5 \mathrm{p}^{2}{ }^{1} \mathrm{D}_{2} \\
5 \mathrm{p}^{2}{ }^{1} \mathrm{~S}_{0}\end{array}$ & $\begin{array}{l}2246.7 \\
2335.5 \\
2434.2 \\
2785.8 \\
3656.8\end{array}$ & $\begin{array}{l}\tau=5.5 \pm 0.6 \mathrm{~ns}^{\mathrm{k}} \\
12.7 \pm 1.6 \\
4.1 \pm 0.5 \\
0.19 \pm 0.02 \\
0.71 \pm 0.09 \\
0.49 \pm 0.06\end{array}$ & $\begin{array}{l}\tau=5.5 \pm 0.4 \mathrm{~ns}^{1} \\
17.9 \pm 2.7 \\
5.8 \pm 0.9 \\
0.26 \pm 0.04 \\
1.01 \pm 0.15 \\
0.69 \pm 0.10\end{array}$ & \\
\hline $\begin{array}{l}5 d^{3} D_{2} \rightarrow 5 p^{2}{ }^{3} P_{1} \\
5 p^{2}{ }^{3} P_{2} \\
5 p^{2}{ }^{1} D_{2}\end{array}$ & $\begin{array}{l}2355.6 \\
2456.0 \\
2814.4\end{array}$ & $\begin{array}{l}\tau=6.8 \pm 0.7 n \mathrm{~s}^{\mathrm{k}} \\
13.5 \pm 1.7 \\
0.17 \pm 0.02 \\
1.1 \pm 0.1\end{array}$ & $\begin{array}{l}\tau=5.5 \pm 0.6 \mathrm{~ns}^{\prime} \\
16.6 \pm 1.7 \\
0.21 \pm 0.02 \\
1.3 \pm 0.1\end{array}$ & \\
\hline $\begin{array}{l}5 d^{3} D_{3} \rightarrow 5 p^{2}{ }^{3} P_{2} \\
5 p^{2}{ }^{1} D_{2}\end{array}$ & $\begin{array}{l}2430.2 \\
2780.6\end{array}$ & $\begin{array}{l}\tau=6.9 \pm 0.7 \mathrm{~ns}^{\mathrm{k}} \\
12.9 \pm 1.7 \\
1.5 \pm 0.2\end{array}$ & $\begin{array}{l}\tau=5.8 \pm 0.6 \mathrm{~ns}^{\prime} \\
15.4 \pm 1.8 \\
1.8 \pm 0.2\end{array}$ & \\
\hline $\begin{array}{l}\text { Moore [56]. } \\
\text { Gorshkov, Vero } \\
\text { Holmgren, Svan } \\
\text { m Lawrence [42] }\end{array}$ & $\operatorname{Ig}[44$ & & & \\
\hline
\end{tabular}

line errors $(<1 \%)$ and the radiative lifetime accuracy $[42,44,46]$. It is significant that there is a good agreement between the values.

\section{Conclusions}

Optical emission spectra of the plasma produced by the $10640 \AA$ Nd:YAG laser of tin-lead sample in vacuum are recorded with a delay with respect to the laser pulse and for a selected interval of time, $0.8 \mu \mathrm{s}$. In this paper, it is shown that laser-induced plasmas are a very interesting spectroscopic source but demanding time resolving spectroscopy for their study.

All the results presented in this paper were obtained using a tinlead sample with $20 \%$ tin concentration to assure optically thin conditions. No self-absorption effects have been detected. The electron temperature $(13200 \mathrm{~K})$ has been determined from the Boltzmann plot method by using the relative emission line intensities of $\mathrm{Sn} \mathrm{L}$, where as the electron number density $\left(2 \times 10^{16} \mathrm{~cm}^{-3}\right)$ is estimated from the Stark broadening profile of the spectral lines of $\mathrm{Sn}$ I. The LTE conditions have been checked.

Spectroscopy analysis of the plasma light emission has been provided with the experimental transition probabilities for 97 emission lines of $\mathrm{Sn}$ I. For 36 of these emission lines, no experimental values of transition probabilities have been made by other authors. A good agreement with previously reference data was found in all cases.

\section{Acknowledgements}

This work has been supported by the project CCG07-UPM/ESP1632 of the TECHNICAL UNIVERSITY OF MADRID (UPM). Support to the lines of UPM investigation groups included in the IV PRICIT of the CAM (Comunidad Autónoma de Madrid), SPAIN.

\section{References}

[1] E.R. Kieft, J.JA.M. van der Muller, G.M.W. Kroesen, V. Banine, K.W. Koshelev, Star broadening experiments on a vacuum arc. Discharge in tin vapour, Physical Review E 70 (066402) (2004) 8 PP.

[2] E.R. Kieft, J.JA.M. van der Muller, G.M.W. Kroesen, V. Banine, K.W. Koshelev, Characterization of a vacuum arc discharge in vapour using time-resolved plasma imaging and extreme ultraviolet spectrometry. Plysical Review E 71 (026409) (2005) $7 \mathrm{pp}$.

[3] M.S. Allen, Tin in the ultraviolet solar spectıum, The Astroplysical Journal 219 (1978) 307-313.

[4] C.H. Corliss, W.R. Bozman, Experimental transition probabilities for spectra lines of seventy elements, National Bureau Standard (U.S.) Monograph, U.S. GPO. Washington. D.C, 1962.

[5] N.P. Penkin. I.Yu.Yu. Slavenas, Oscillator strengths of the spectral lines Sn I and Pb I, Optics and Spectroscopy (USSR) 15 (1963) 83-88.

[6] G.M. Lawrence, J.K. Link, R.B. King, The absolute oscillator strengths of lines in the spectra of ten elements, The Astrophysical Journal 141 (1965) 293-307.

[7] G.V. Ovechkin, Sh. Bakhtovarshoev, L.E. Sandrigailo, Detemmination of transition probabilities for weak lines of magnesium and tin, Journal of Applied Spectroscopy 7 (1967) 309-312.

[8] R.L. DeZafra, A. Marshall, Lifetimes and oscillator strengths for the ${ }^{3} \mathrm{P}_{\mathbf{1}}$ atomic states of Pb and Sn, Physical Review 170 (1968) 28-36.

[9] J. Lotrian, J. Cariou, A Johannin-Gilles, Determination of the oscillator strengths of Sn(I) in the ultraviolet (2400-4000 A). Journal of Quantitative Spectroscopy Radiative Transfer 16 (1976) 315-319.

[10] T. Wujec, ]. Musielok, Measurements of absolute transition probabilities of Sn I and Sil II lines by method of emission spectroscopy. Astronomy \& Astroplysics 50 (1976) 405-411.

[11| T. Wujec, S. Weniger, Atomic transition probabilities for Sn (I). Sn(II) and Cl(I) lines in the 5300-6850 A wavelength range, Journal of Quantitative Spectroscopy Radiative Transfer 18 (1977) 509-514.

|12| M.H. Miller, R.A. Roig. R.D. Bengtson, Experimental transition probabilities and Stark broadening parameters of neutral and singly ionized tin, Physical Review A $20(1979) 499-506$.

[13| V.G. Muradov, Determination of the relative oscillator strengths of $51 \mathrm{I}$ lines and evaluation of the hyperfine splintting of $5^{3} \mathrm{D}_{1}$ and $6{ }^{3} \mathrm{P}_{2}$ levels using line absortion measurements, Optics and Spectroscopy (USSR) 46 (1979) $476-478$.

[14] L. Holmgren, S. Garpman, A relativistic calculation of transition probabilities between the $n p(n+1) s$ and $n p^{2}$ configurations for the elements of group IV. Pluysica Sclipta 10 (1974) 215-220.

[15] J. Migdalek, Relativistic oscillator strengths for $n p^{2} \rightarrow n p(n+1)$ s transition array of $\mathrm{Sn} \mathrm{I}$ and $\mathrm{Pb} I$ spectra in $\mathrm{j}$ and intermediate coupling. Candalian Journal of Physics 57 (2) (1979) 147-151.

[16] P.S. Gallas, Optical oscillator strengths for germanium, tin, and lead, Journal of Applied Plysics 65 (3) (1989) 905-907.

[17] P.F. Gruzdev, Oscillator strengths of the resonance lines of Ge I, As II, Sn I, Sb II, Pb I, and Bi II, Optics and Spectroscopy (USSR) 25 (1) (1968) 1-5.

[18] J.R. Bieron, R. Marcinek, J. Migdaek, Relativistic oscillator strengths for the $n p^{2}-n p$ $(n+1)$ s transitions, Journal of Physics B: Atomic, Molecular and Optical Physics 24 (1991) 31-43.

[19] E. Biémont, ].E. Hansen, P. Quinet, C.J.Zeippen, Forbidden transitions of astrophysical interest in the $5 p^{k}(k=1-5)$ configurations, Astronomy \& Astrophysics Supplement Series 111 (1995) 333-346.

[20] LJ. Curtis, Use of intermediate coupling relationships to test measured branching fraction data, Joumal of Physics B: Atomic, Molecular and Optical Physics 31 (1998) L769-L774.

[21| LI. Curtis, Branching fractions for the $5 s^{2} 5 p^{2}-5 s^{2} 5 p 6 s$ supermultiplet in the Sn I isoelectronic sequence, Journal of Physics B: Atomic, Molecular and Optical Physics 63 (2001) 104-107.

|22| Y.J. Yu, C.Z. Dong. J.G. Li, B. Fricke, The excitation energies, ionization potentials, and oscillator strengthe of neutral and ionized species of Uuc $(Z=114)$ and the homolog elements Ge, Sll, alr Pb, Joumal of Chemical Plysics 128 (124216) (2008) 7 Pp.

[23] P.Oliver, A Hibbert, Energy level classifications and Breit-Pauli oscillator strengths in neutral tin, Joumal of Physics B: Atomic, Molecular and Optical Physics 41 (1165003) (2008) $13 \mathrm{PP}$

[24] A. Nadeem, A. Ahad, S.A. Bhatti, N. Ahmad, R. Ali, M.A. Baig, Two-step laser spectroscopy of the even-parity Rydberg levels of neutral tin, Journal of Plysics B: Atomic, Molecular and Optical Physics 32 (1999) 5669-5679. 
[25] A. Nadeem, SA. Bhatti, N. Ahmad, MA. Baig. Two-step laser excitation of 5p 3 illp, nf $\mathrm{J}=1$ and 2 autoionizing Rydberg levels of tin, Journal of Physics B: Atomic, Molecular and Optical Physics 33 (2000) 3729-3741.

[26] A. Nadeem. SA. Bhatti, N. Ahmad, M.A. Baig. Two-step laser excitation of $5 \mathrm{p}_{1,2}$ lip nf $\mathrm{j}=1,2$ Rydberg levels of neutral tin, Journal of Physics B: Atomic, Molecular and Optical Pliysics 34 (2001) 2407-2417.

[27] C. Pasquini, ]. Cortez, LM.C. Silva, F.B. Gonzaga, Laser induced breakdown spectroscopy, Journal of the Brazilian Chemical Society 18 (3) (2008) 463-512.

[28| L.]. Radziemski, D.A. Cremers, Laser-Induced Plasma and Applications, Dekker, New York, 1989.

[29] D.A. Cremers, L.]. Radziemski, Handbook of Laser-induced Breakdown Spectroscopy: Methods and Applications, John Wiley \& Sons, New York, 2006.

[30| JA Aguilera, C. Aragón, Characterization of a laser-induced plasma by spatially resolved spectroscopy of neutal atom and ion emissions. Comparison of local and spatially integrated measurements, Spectrochimica Acta Part B 59 (2004) 1861-1876.

[31] ].A. Aguilera, C. Aragón. Apparent excitation temperature in laser-induced plasina, Journal of Physics 59 (2007) 210-217 Conference Series.

[32] ].A. Aguilera, C. Aragón. Characterization of a laser-induced plasma by emission spectroscopy with curve-of-growth measurements, Part I: Temporal evolution of plasma parameters and self-absorption, Spectrochimica Acta Part B 63 (2008) 784-792.

[33] M. Milán, J.]. Laserna, Diagnostics of silicon plasma produced by visible nanosecond laser ablation, Spectroclimica Acta Part B 56 (2001) 275-288.

[34] X. Hou, L. Pan, Y. Sun, Y. Li, Y. He, H. Oj. Study of the plasina produced from laser ablation of a LBO crystal, Appied Surface Science 227 (2004) 325-330.

[35] Be Martínez, F. Blanco, Experimental and theoretical Stara width and shift parameters of neutral and singly ionized tin lines, Journal of Physics B: Atomic, Molecular and Optical Physics 32 (1999) 241-247.

[36] A. Alonso-Medina, C. Colón, Interpretation of the spectrum of Sn II: Experimental and theoretical transition probabilities, Physica Scripta 61 (2000) 646-651.

[37] A. Alonso-Medina, C. Colóln, C. Herrán-Martinez, Transitions from auto ionized single-ionized tin states: A theoretical study of the $5 \mathrm{~s} 5 \mathrm{p}(3 \mathrm{P} 0) \mathrm{l}(\mathrm{nl}=5 \mathrm{~d}, 6 \mathrm{~s})$ levels of Sn II, The Astrophysical Journal 595 (2003) 550-554.

[38| 5.5. Harilal, B. O Shay, M.S. Tillack. Spectroscopic characterization of laser-induced tin plasma, Journal of Applied Physics 98 (013306) (2005) 7 pp.

[39| 5.5. Harilal, Influence of spot size on propagation dynamics of laser-produced tin plasma, Joumal of Applied Physics 102 (123306) (2007) $6 \mathrm{pp}$.

[40] A. Alonso-Medina, C. Colón, Measured stark widths of several Sn I and Sn II spectral lines in a laser induced plasma. The Astrophysical Journal 672 (2008) $1282-1291$.

[41] Y.Zhang. J.-X.Xu, W. Zhang, S. You, Z.-G. Ma, L.-L., Han, P.-F. Li, G.-J. Sun, Z.-K. Jiang, S. Enzonga Yoca, P. Quinet, E. Biémont, Z.-W. Dai, Lifetime and Landé factor measurements of $5 p^{7} p$ levels of $\mathrm{S}$ I by time-resolved laser spectroscopy, Physical Review A 78 (2008) 022505.

[42] G.M. Lawrence, Resonance transition probabilities in intemmediate coupling for some neutral non-metals, The Astrophysical Joumal 148 (1967) 261-267.
[43] M. Brieger, P. Zimmermann, Level crossing investigation of the hyperfine structure of $\mathrm{Sn}^{113}$ and $\mathrm{Sn}^{119}$ for the $(5 \mathrm{p} 6 \mathrm{~s}){ }^{3} \mathrm{P}_{1}$ term of the $\mathrm{S} n \mathrm{I}$ spectrum, Zeitschrift für Naturforsclung-Teil A 22 (1967) 2001.

[44] L. Holmgren, 5. Svanberg. Natural radiative lifetimes of the 5p6s 1P1, 5p6s 3P1, and 5p5d 3D1, 2, 3 levels of the $\mathrm{Sn} I$ spectrum by zero field level crossing spectroscopy. Physica Sclipta 5 (1972) 135-137.

[45] T. Andersen, O.H. Madsen, G. Sorensen, Radiative lifetimes in $\mathrm{S}$ I and Bi I, Journa of the Optical Society of America 62 (1972) 1118.

[46] V.N. Gorshkov, Ya.F. Verolainen, Radiative lifetimes of Sn I and Sn II excited states, Optics and Spectroscopy (USSR) 59 (1985) 694-699.

[47] A. Alonso-Medina, Transition Probabilities of $30 \mathrm{~Pb}$ II lines of the spectrum obtained by emission of a laser-produced plasma, Physica Scripta 55 (1997) 49-53.

[48] C. Colón, A. Alonso-Medina, C. Herrán-Martínez, Spectroscopy study of a laserproduced lead plasma: experimental atomic tansition probabilities for Pb III lines, Joumal of Physics B: Atomic, Molecular and Optical Physics 32 (1999) 3887-3897.

[49] A. Alonso-Medina, C. Colól, C. Herrán-Martinez, Experimentally detelmnined transition probabilities for lines of $\mathrm{Pb} \mathrm{I}$ and $2203.5 \AA$ line of $\mathrm{Pb}$ II, Journal of Quantitative Spectroscopy \& Radiative Transfer 68 (2001) 351-362.

[50] C.Colón, A. Alonso-Medina, Application of a lasel produced plasma: experimental Starl widths of single ionized lead lines, Spectrochimica Acta Part B 61 (2006) 856-863.

[51] A. Alonso-Medina, C. Colón, Stark widtlis of several Pb III spectral lines in a laserinduced lead plasma, Astronomy \& Astrophysics 466 (2007) 399-402.

[52] A.Alonso-Medina, Experimental determination of the Stark widths of $\mathrm{Fb} I$ spectral lines in a laser-induced plasma, Spectrochimica Acta Part B 63 (2008) 598-602.

[53] W. Lochte-Holtgreven, in: W. Lochte-Holtgreven (Ed.), Plasma Diagnostics, NorthHolland. Amsterdam, 1968.

[54] C. Aragón, JA. Aguilera, Characterization of Laser induced plasma by optical emission spectroscopy: a review of experiments and methods, Spectrochimica Acta Part B (2008) 893-916.

[55] H.R Griem, Spectral Line Broadening by Plasma, Academic Press, New York, 1974.

[56] G. Befeki. Principles of Laser Plasmas, Wiley Interscience, New York, 1976.

[57] C.E. Moore, Atomic Energy Levels NBS 467 vol III, U.S.GPO, Washington D.C, 1958 p. 208.

[58] I.B. Gormushkin, L.A. King, B.W. Smith, N. Omenetto, J.D. Winefordner, Line broadening mechanisms in the low pressure laserinduced plasma, Spectrochimica Acta Part B 54 (1999) 1207-1217.

[59] V. Milosavljevic, G. Poparic, Atomic spectra line free parameter deconvolution procedure, Physical Review E 63 (036404) (2001) 7.

[60] P.J. Wolf, The plasma properties of laser-ablated $\mathrm{Si}_{2}$, Journal of Applied Plysics 72 (1992) 1280-1289.

[61] N. Konjevic, Plasma broadening and shifting of non-hydrogenic spectal lines: present status and applications, Physics Reports 316 (1999) 339-401.

[62] RW.P. McWhirter, Plasma Diagnostic Technics Huddlestone R H\& Leonard S L New York Academic, 1963.

[63] A.P. Thorne, Spectrophysics, 2nd editionChapman and Hall, London, 1988.

[64] A. Corney. Atomic and Laser Spectroscopy, Oxford University Press, 1977. 